\title{
O PRINCÍPIO CONSTITUCIONAL DA EFICIÊNCIA NA ADMINISTRAÇÃO PÚBLICA
}

\author{
Juliano Henrique da Cruz Cereijido*
}

1. Conceito e delimitação. 2. Eficiência do ato administrativo. 3. Eficiência na licitação e na celebração de contratos administrativos. 4. Eficiência e poder de polícia. 5. Eficiência dos agentes públicos. 6. Eficiência na prestação de serviços públicos. 7. Eficiência na administração de "res"pública - Visão crítica. Bibliografia.

1. - CONCEITO E DELIMITAÇÃO - Embora a doutrina tenha mostrado alguma relutância em acolher a eficiência, mesmo como princípio constitucional implícito, antes da Reforma Administrativa, aparentemente sempre houve certo censo em incluí-la junto às diretrizes da atuação dos agentes públicos, tanto que Hely Lopes Meirelles já o fazia na qualidade de poder-dever do administrador público.

Introduzida pela Emenda Constitucional $n^{\circ} 19$, de 4 de junho de 1998, a eficiência foi elencada ao lado da legalidade, impessoalidade, moralidade e publicidade, como um dos princípios expressos da Administração Pública, nos termos do novo caput do artigo 37 da Constituição Federal. Podendo ser tida como parte de um esforço agressivo empreendido pelo Governo Federal para a implementação da chamada "administração gerencial", sucessora da "administração burocrática", a formalização do princípio da eficiência teria como pressupostos, como deixou patente o próprio Chefe do Executivo, a flexibilização dos padrões hierárquicos rígidos e concentração no controle dos resultados e não dos meios ${ }^{1}$, premissa esta relacionada de maneira equívoca, como veremos.

Cremos que o controle da eficiência, mais que o controle finalístico, está intrinsecamente relacionado com os meios empregados ${ }^{2}$. Nesse passo, conceituamos o princípio da eficiência nos seguintes termos: Trata-se de norma principiológica destinada a conferir aos agentes públicos o dever de selecionar e utilizar criterio-

1 Plano Diretor da Reforma do Aparelho do Estado, p. 10.

2 Entendimento, por sinal, já defendido no magistério autorizado de José Eduardo Martins Cardozo, durante conferência na Escola Superior do Ministério Público de São Paulo, em 1999.

* Procurador da Assembléia Legislativa de São Paulo. 
samente os melhores meios a serem empregados no cumprimento das atividades necessárias à boa administração, voltada ao atingimento de sua finalidade legal e, em última análise, do interesse público que lhe dá embasamento e legitimidade.

O controle dos meios (e não nos fins alcançados), seria regra, o que entendemos, a propósito, mais condizente com a legalidade e especialmente moralidade administrativas.

Todavia, a aplicação do princípio da eficiência não pode ser dissociada de sua conjugação com outros princípios igualmente importantes e que acabam funcionando como uma espécie de "sistema de freios e contrapesos" da Administração Pública.

Exemplificando, a escolha dos melhores meios não pode ser de tal forma onerosa à Administração Pública que os resultados alcançados sejam suplantados pela contrapartida excessiva daí advinda. Os meios escolhidos, além de razoáveis, deverão ainda ser proporcionais. Concordando com os autores que vêem o princípio da proporcionalidade como uma decorrência da razoabilidade, entendemos que estes dois princípios deverão, juntamente com os demais, servir como parâmetro ao agente público que pretenda, atendendo aos ditames constitucionais, dar azo ao princípio da eficiência.

Não seria admissível, na hipótese aventada, a aquisição pela Administração de um equipamento de altíssimo custo para um trabalho de curta duração, que outro equipamento mais modesto faria em tempo pouco maior, sem haver sequer situação emergencial que eventualmente pudesse justificar tal atitude.

Utilizando o exemplo proposto, embora aparentemente tal aparato tecnológico fosse muito mais eficiente, a sua utilização esporádica ou sem previsão de utilização em larga escala faria com que a economia do fator tempo fosse absolutamente inviabilizada pela alta onerosidade econômica advinda com a aquisição, e que acabaria tendo de ser absorvida pelo erário, sem qualquer retorno, ainda que social.

$\mathrm{O}$ ato, embora se pretenda deduzir suposta eficiência da Administração na prestação de um serviço público, acaba pecando pela ausência de razoabilidade e mesmo inobservância da proporcionalidade. É óbvio, contudo, que a eficiência na Administração Pública não se resume em agir com razoabilidade ou com proporcionalidade, ou simplesmente agir tendo em mira a finalidade legal.

O administrador público, como qualquer cidadão, não podendo estar acima da Lei Maior, deve a ela conformar-se, sendo-lhe vedado, sob a alegação de estar atendendo a um princípio constitucional, violar outro. Sob uma abordagem constitucional, a aplicabilidade dos princípios jungidos à Administração Pública convergem na fusão de todas as qualidades, morais e técnicas, que se pretende existam em um administrador, cioso da imensa responsabilidade que compete àqueles que lidam com o dinheiro público e da infatigável expectativa da coletividade que lhe delegou poderes para o bom cumprimento de sua munus, voltada ao atingimento do interesse público.

Um administrador eficiente é, antes de tudo, um cidadão que deve estar preparado intelectualmente e em constante sintonia com as ininterruptas evoluções metodológicas e tecnológicas, típicas de um mundo extremamente complexo.

Como veremos a seguir, a eficiência na Administração Pública é matéria passível de ser abordada sob vários ângulos, espraiando-se por diversos campos do Direito Administrativo. Se a Administração Pública brasileira, com a complexidade que lhe 
é peculiar, desdobra-se em inúmeras e distintas entidades, pertencentes a diferentes entes da federação, ligados à administração direta ou indireta, por vezes mesmo constituídas de apêndices com natureza jurídica privada, subdivididas em órgãos com especializadas atribuições e diferentes prerrogativas de seus agentes, que os conduzem na exata medida de suas funções e posição ocupada, poderíamos, ainda que timidamente, tentar organizar, diante desse quadro, as diferentes concepções do princípio da eficiência.

Sem a pretensão de esgotar a matéria, pelo contrário, contribuir para uma melhor sistematização, já que pouco estudada, e aproveitando conceitos consagrados e extraídos da melhor doutrina, tentaremos demonstrar que o novo instituto da eficiência é possível de ser assimilado e inserido como parte componente das matérias mais tradicionalmente tratadas pelo Direito Administrativo no Brasil.

\section{2. - EFICIENNCIA DO ATO ADMINISTRATIVO - Caberia falar em eficiência} face aos atos administrativos vinculados? E em relação aos atos discricionários? Qual seria a exata delimitação do instituto em relação aos atos administrativos? A eficiência pode ser tida como elemento ou requisito do ato administrativo?

Nossas atenções serão concentradas naquelas teorias que procuram, de maneira científica, desnudar o ato administrativo, prescrutando eventuais vícios que possam se ocultar sob uma pretensa regularidade. Decomposto o ato administrativo, em fragmentos que a doutrina denomina requisitos, elementos ou pressupostos, por vezes combinando-se as terminologias, verificaremos que a temática da eficiência pode e deve ser incluida cientificamente no âmago dessas teorias, encontrando supedâneo na própria Constituição, que acaba por irradiar seus efeitos sobre todo o Direito Administrativo.

Hely Lopes Meirelles ${ }^{3}$ afirmava existir nos atos administrativos a presença de cinco requisitos, que seriam necessários à sua formação, a saber: a) competência, ou o "poder atribuído ao agente da Administração para o desempenho específico de suas funções"; b) finalidade, caracterizada com o "objetivo de interesse público a atingir", indicado explícita ou implicitamente pela Lei; c) forma, qualificada com o "revestimento exteriorizador do ato administrativo" e que constitui "requisito vinculado e imprescindível à sua perfeição"; d) motivo, ou "situação de direito ou de fato que determina ou autoriza a realização do ato administrativo", e e) objeto, que se identificaria com o "conteúdo do ato". 4

3 Direito administrativo brasileiro, p. 133-137.

4 O mesmo entendimento é partilhado por Maria Sylvia Zanella di Pietro (Direito Administrativo, p. 187), que prefere enumerar, no que denomina elementos do ato administrativo, o "sujeito" em lugar da "competência": "Apenas com relação à competência é preferível fazer referência ao sujeito, já que a competência é apenas um dos atributos que ele deve ter para validade do ato; além de competente deve ser capaz, nos termos do Código Civil". Discordando de tais posicionamentos, que não são os únicos nesse sentido, Celso Antônio Bandeira de Mello (Curso de Direito Administrativo, p. 335) observa que nem todos os costumeiramente denominados "elementos" do ato administrativo teriam tal característica: "É fácil perceber-se que, dentre estes chamados 'elementos', nem todos realmente o são. Donde a impropriedade do uso da palavra para designar o conjunto batizado sob tal rótulo. Com efeito, o temo 'elementos' sugere a idéia de 'parte componente de um 
Para Celso Antônio Bandeira de Mello, somente seriam efetivamente elementos do ato administrativo o conteúdo e a forma, ao passo que existiriam ainda os seus pressupostos, de existência e de validade, com suas respectivas subdivisões ${ }^{5}$. O conteúdo, que alguns autores chamam "objeto", seria "aquilo que o ato dispõe, isto é, o que o ato decide, enuncia, certifica, opina ou modifica na ordem jurídica". Já a forma não se confundiria com a "formalização", um dos pressupostos, como veremos adiante. Juntos formariam os elementos do ato administrativo. Sem os elementos inexistiria "o próprio ser que se designa pelo nome de ato jurídico." 6

Contudo, o grande diferencial da lição do ilustre administrativista está no que denominou pressupostos do ato administrativo, divididos em dois grandes blocos: os pressupostos de existência e os pressupostos de validade. O primeiro pressuposto de existência seria o objeto, ou seja, "aquilo a que o ato dispõe", acompanhado da pertinência à função administrativa, que caracterizar-se-ia pela necessidade de que o ato seja imputável ao Estado. Sem estes pressupostos, o ato não existiria ou existiria sob forma diversa do ato administrativo. Os pressupostos de validade, sem os quais não haverá ato administrativo válido, onde inseriremos o "agir eficientemente", seriam subdivididos em pressuposto subjetivo, pressupostos objetivos, pressuposto teleológico, pressuposto lógico e pressuposto formalístico. ${ }^{7}$

Assim colocada toda a teoria, com a devida vênia, tomamos a liberdade de acrescentar, face ao mais novo princípio informador da Administração Pública, mais um pressuposto de validade objetivo do ato administrativo, ao lado do motivo e dos requisitos procedimentais: a eficiência.

Se é certo que a eficiência não pode ser tida como um dos elementos do ato administrativo, já que este existirá independentemente de ser eficiente ou não,o mesmo não poderia ser dito em relação à possibilidade de produzir efeitos válidos.

Todo e qualquer ato administrativo será, portanto, inválido, nas hipóteses em que não exteriorize comando que contenha, de maneira objetiva, aptidão para produzir seus efeitos de maneira eficiente. $O$ ato administrativo, além dos demais pressupostos de validade, deverá ainda trazer em seu bojo comandos dotados de capacidade para aferir efeitos práticos quanto à eficiência do ato.

Dessa forma, na tradicional conceituação doutrinária que elenca unicamente os assim denominados elementos do ato, a eficiência deveria estar figurando juntamente com o sujeito, a forma, a finalidade, o motivo e o conteúdo.

Contudo, como é que fica a questão do ato administrativo eficiente face às teorias da vinculação e da discricionariedade? Como propomos no início desse tópico, caberia falar em eficiência face aos atos administrativos vinculados? E em relação aos atos discricionários?

todo'. Ocorre que alguns deles, a toda evidência, não podem ser admitidos como 'partes' do ato, pois lhe são exteriores, conforme se verá adiante, ao tratarmos destes distintos tópicos".

5 Trata-se certamente de um dos mais analíticos estudos brasileiros sobre a natureza dos atos administrativos, dele tratando de maneira supostamente exauriente. Diante dessa condição, vamos aproveitá-lo para desenvolver a tese que nos propusemos a dissertar.

6 Curso de direito administrativo, p. 335-353.

7 Curso de direito adminisrativo, p. 335-353. 
Para agirmos de maneira objetiva, e utilizando doutrina que é aceita pela maioria dos autores, a discricionariedade face aos atos administrativos estaria focalizada no motivo e no conteúdo (para alguns, objeto). Em relação ao sujeito (ou competência), à forma e à finalidade (em sentido estrito) ${ }^{8}$, o ato administrativo seria sempre vinculado, não existindo liberdade de escolha e de agir ao administrador público. Em relação ao motivo e ao conteúdo, $o$ ato poderá ou não ser discricionário, conforme a lei se abstenha ou não se prevê-los.

Se a lei prescreve àquele determinado ato administrativo, dentro do conceito de eficiência a que nos propomos no início deste trabalho, os meios a serem empregados para aquela determinada tarefa ou atividade, então o ato será vinculado, impondo a norma as ações que entende necessárias à plena caracterização do princípio constitucional.

De outro turno, se a lei apresenta lacuna ou se omite nesse sentido, confere-se ao administrador liberdade da escolha daqueles meios que virão a se caracterizar como garantidores da eficiência da medida, sendo o ato, nesse aspecto, discricionário.

\section{3. - EFICIÊNCIA NA LICITAÇÃO E NA CELEBRAÇÃO DE CONTATOS} ADMINISTRATIVOS - A Administração Pública, diante da especial condição que desfruta em relação aos particulares, foi costeada de certas regras específicas que dizem respeito àqueles atos necessários ao cumprimento de suas finalidades e manutenção da máquina estatal, como por exemplo, adquirir, alienar e locar bens, contratar serviços e obras etc. Para tanto, existe o instituto administrativo da licitação, que é o nome genérico conferido a todos os procedimentos que tenham por fim realizar tais atos, com as devidas ressalvas, previstas também em lei.

Cumpre asseverar, sem maiores delongas, que a eficiência, não obstante não elencada no artigo $3^{\circ}$ da lei federal de licitações e contratos administrativos, entre os seus princípios, como norma principiológica destinada a toda a Administração Pública, acaba por irradiar seus efeitos e imiscuir-se nos mais diversos campos da disciplina. Nesse passo, se a licitação pode ser estendida como procedimento prévio às contratações pela Administração Pública, garantindo através do princípio da isonomia e demais princípios, o acesso a todos aqueles que estejam aptos a atender de maneira objetiva às suas necessidades, nos termos da lei, poderíamos afirmar que deverá ser utilizada também como forma de assegurar que o Poder Público procederá de maneira eficiente a definição do objeto e a seleção dos possíveis

8 A doutrina tradicional elenca a finalidade como parte integrante do ato que é sempre vinculada. Entretanto, autores como Celso Antônio Bandeira de Mello e Maria Sylvia Zanella Di Pietro afirmam que a assertiva não é totalmente verdadeira. Para a autora, não obstante seja a finalidade do ato em sentido restrito (que "corresponde ao resultado específico que decorre, explícita ou implicitamente da lei, para cada ato administrativo") sempre vinculada, em sentido amplo, que deve corresponder ao interesse público, será discricionária "porque a lei se refere a ela usando noções vagas e imprecisas, como ordem pública, segurança, moral, bem-estar" (Direito administrativo, p. 199). Para o autor, embora o fim seja sempre vinculante, a "qualificação do interesse público comporta certa margem, delimitada, é certo, do juízo discricionário" (Curso de direito administrativo, p. 369). 
interessados, mesmo nas hipóteses de contratação direta, cuidando para que atuem também eficientemente.

Como já salientado, o procedimento licitatório envolve uma série de atos administrativos que devem, para serem tidos como válidos, ser produzidos de forma a visar a eficiência. Dessa forma, qualquer que seja a modalidade licitatória, formalizada através de edital ou carta-convite, deverá ser realizada de modo a selecionar criteriosamente as características técnicas e os meios mais adequados ao atingimento dos fins a que se destina a contratação.

É sabido que a diferença entre uma boa contratação e outra sofrível, de um mesmo bem, serviço ou obra, estará lastreada fundamentalmente na sua adequada descrição, especialmente quando se tratar de licitação tipo menor preço. A necessidade do administrador público agir eficientemente, por óbvio, é regra mesmo naquelas avenças a que se prescreva ou faculte contratações diretas, ou seja, que impliquem respectivamente em inexigibilidade e dispensa de licitação.

Tendo o agente, nessas hipóteses, o dever de motivar, deverá fazê-lo de modo a deixar caracterizado não só o cumprimento ao imperativo legal, consubstanciado na subsunção fática à norma permissiva, mas também a demonstração que a escolha do fornecedor levou em conta a eleição daquele que ofereça produto ou serviço que empregue os melhores meios ou métodos disponíveis para alcançar o resultado desejado.

4. - EFICIÊNCIA E PODER DE POLÍCIA - Idéia surgida no período da democracia ateniense e lapidada através do tempo, em meio a períodos de obscurantismo, a noção de que deveria existir um interesse acima do pessoal, que abrangesse e beneficiasse toda uma coletividade, sempre habitou latente na própria razão de ser do Estado.

Vedados os abusos que excedessem os estreitos limites da legalidade e dos demais princípios, o poder de polícia firmou-se como aquela zona intermediária que atua sobre a liberdade e propriedade pessoal de forma a garantir o bem-estar social, como observa Celso Antônio Bandeira de Mello. Ressalvando que a defesa dos interesses públicos acaba por impor a utilização de meios coativos, através do exercício do poder de polícia pela Administração Pública, este mesmo autor traça um interessante paralelo entre o princípio da proprocionalidade e a sua utilização como antídoto em face de eventuais abusos da Administração, alertando que a esta cumpre se comportar "com extrema cautela, nunca se servindo de meios mais enérgicos que os necessários à obtenção do resultado pretendido pela lei". 9 .

Cremos que juntamente com a aplicação do critério da proporcionalidade, bem ressaltada pelo ilustre administrativista, a Emenda Constitucional $n^{\circ} 19 / 98$ consolidou a obrigatoriedade do emprego dos meios mais eficientes para a obtenção do resultado pretendido, posto que a utilização de procedimentos sem tal qualidade constituem, tanto quanto a adoção de ações desproporcionais, violência desnecessária e invasão indevida à liberdade e propriedade individuais, que a busca do atingimento 
do interesse público, com toda a importância que lhe é inerente, não pode desconsiderar.

Em outras palavras, o princípio da eficiência assume papel tão importante quanto os princípios da razoabilidade e da proporcionalidade, à medida que a sua não observância nos atos coercitivos decorrentes do poder de polícia podem trazer agressão tão grande aos direitos e garantias fundamentais, especialmente aos valores da liberdade e da propriedade, os mais afetados pelo exercício de tal limitação administrativa, quanto seria aquela esperada pela inaplicabilidade destes últimos e dos demais princípios da Administração Pública.

5. - EFICIENNCIA DOS AGENTES PÚBLICOS - Vale ressaltar que boa parte das inovações trazidas à esfera jurídica dos agentes públicos, com a Emenda Constitucional $n^{\circ} 19 / 98$, acabam por trazer de maneira direta ou indireta consequências face à aplicação do princípio da eficiência. Como melhor exemplo do que afirmamos, o procedimento de avaliação periódica de desempenho, tornado obrigatório e fonte da perda do cargo ao servidor estável em caso de insuficiência, previsto na nova redação do artigo 41 da Carta Magna, de certa forma institucionaliza o princípio junto aos quadros de pessoal da Administração Pública.

$\mathrm{Na}$ forma da Lei Complementar, o não cumprimento de níveis mínimos de desempenho acabaria por relativizar um dos "dogmas" do funcionalismo público, ou seja, a estabilidade do servidor público efetivo, até então somente excepcionável nas hipóteses de sentença judicial transitada em julgado e processo administrativo em que the fosse assegurado a ampla defesa.

A título ilustrativo, Lei $n^{\circ} 8.112$, de 11 de dezembro de 1990 , que dispõe sobre o Regime Jurídico dos Servidores Públicos Civis da União, das Autarquias e das Fundações Públicas Federais, ao tratar dos casos em que seria aplicável a demissão. enumera em seu artigo 132, as seguintes hipóteses: a) crime contra a Administração Pública; b) abandono do cargo; c) inassiduidade habitual; d) improbidade administrativa; e) incontinência pública e conduta escandalosa, na repartição; f) insubordinação grave em serviço; $g$ ) ofensa física, em serviço, a servidor ou a particular, salvo em legítima defesa própria ou de outrem; $h$ ) aplicação irregular de dinheiros públicos; i) revelação de segredo do qual se apropriou em razão do cargo; j) lesão aos cofres públicos e dilapidação do patrimônio nacional; 1) corrupção; m) acumulação ilegal de cargos, empregos ou funções públicas; $n$ ) transgressão dos incisos IX a XVI do artigo 117.

Portanto, não existe no elenco, até então numerus clausus, qualquer hipótese do que ora intitulamos fator intrínseco ao desempenho funcional,ou seja, aquele relacionado com o desempenho na própria atividade especificamente considerada, para o qual foi o servidor admitido no serviço público; mas sim atos praticados quando do desempenho funcional, que denominaremos fator extrínseco ao desempenho funcional.

Um servidor que atue na tesouraria de um órgão público e causa lesão ao erário de forma a desviar tais recursos em proveito próprio estará se aproveitando da situação fática, ou seja, o desempenho de uma função pública naquele local, para agir de maneira ilícita, evidenciando ato que estamos denominando fato extrínseco de desempenho. 
Diferentemente, um servidor habilitado em ciências contábeis que atue no mesmo local e causa lesão ao erário por reiteradas falhas e omissões graves em seu trabalho usual, de modo a manifestar evidente déficit no desempenho que seria esperado de alguém admitido para tão importante função, estaria evidenciando hipótese em que atua o fator intrínseco ao desempenho funcional, que o dispositivo contido no inciso III do parágrafo $1^{\circ}$ do artigo 41 da Constituição Federal procurou abranger.

A existência do concurso, pressuposto prévio da admissão e conquista futura da estabilidade pelo servidor efetivo, era vista, aprovado o candidato, como suficiente para garantir a contínua habilitação do candidato para o desempenho do cargo ou função. Essa mentalidade foi exatamente o que a nova redação do artigo 41 da Carta Magna procurou atacar. Buscar-se-ia o contínuo aperfeiçoamento e atualização dos servidores, de modo a adaptá-los e motivá-los a se prepararem às contínuas mudanças tecnológicas e operacionais. Isso supostamente acabaria por fazer com que o servidor atuasse de maneira necessariamente mais eficiente, na busca do aprimoramento funcional e profissional.

Cremos, contudo, que se trata da eficiência simplesmente na acepção da maior produtividade, mas principalmente, na eficiência que diz respeito aos ganhos qualitativos de desempenho e que garantem um serviço público condizente com um cidadão mais exigente e cioso de seus direitos. Tal idéia, longe de ser original, já era ministrada por Hely Lopes Meirelles, somando-se a outros dos chamados poderes-deveres do administrador público ${ }^{10}$. Por certo a mesma conclusão se estende a todo agente público, não só aos "administradores", e até mesmo ao particular que preste serviços de natureza pública.

6. - EFICIENNCIA NA PRESTAÇÃO DE SERVIÇOS PÚBLICOS - Os serviços públicos, na definição de Maria Sylvia Zanella di Pietro, corresponderiam a "toda atividade material que a lei atribui ao Estado para que a exerça diretamente ou por meio de seus delegados, com o objetivo de satisfazer concretamente às necessidades coletivas, sob regime jurídico total ou parcialmente público"." Seriam, por sua vez, princípios relativos à matéria o da continuidade dos serviços públicos, o da mutabilidade do regime jurídico e o da igualdade dos usuários ${ }^{12}$, a que acrescentaríamos a eficiência na prestação dos serviços públicos, como veremos.

10 A respeito, Hely Lopes Meirelles vaticinava que: "a eficiência funcional é, pois, considerada em sentido amplo, abrangendo não só a produtividade do exercente do cargo ou da função como a perfeição do trabalho e sua adequação técnica aos fins visados pela Administração, para o quê se avaliam os resultados, confrontam-se os desempenhos e se aperfeiçoa o pessoal através de seleção e treinamento. Assim, a verificação da eficiência atinge os aspectos quantitativo e qualitativo do serviço, para aquilatar do seu rendimento efetivo, do seu custo operacional e da sua real utilidade para os administrados e para a Administração. Tal controle desenvolve-se, portanto, na tríplice linha administrativa, econômica e técnica" (Direito Administrativo Brasileiro, p. 99).

11 Direito administrativo, p. 98.

12 Ibid., p. 100. 
A respeito, o Plano Diretor da Reforma do Aparelho do Estado, como já observamos anteriormente, liga a noção de Administração Pública Gerencial a uma maior eficiência na prestação dos serviços públicos. Fala-se de maneira espontânea em fixação de objetivos a serem atingidos, podendo inclusive serem contratados, autonomia na gestão dos recursos e mesmo no controle a posteriori dos resultados, numa fórmula próxima à gestão empreendida nas empresas privadas. Além disso, o cidadão passaria a ser visto como contribuinte de impostos e "cliente", de forma que o importante passe a ser a sua plena satisfação. ${ }^{13}$

Daí o referido documento mencionar, de maneira equivocada, a não importância dos meios, desde que os fins sejam atingidos, consubstanciados na prestação de um serviço público de qualidade, ou seja, a chamada Administração Pública Gerencial estaria "voltada à cidadania" e devolução do Estado à sociedade, numa gestão eficiente da "res" pública".

Para os idealizadores do Plano Diretor da Reforma do Aparelho do Estado, a eficiência restringir-se-ia ao binômio qualidade e baixo custo, junto aos setores de atividades exclusivas e de serviços competitivos ou não-exclusivos. ${ }^{15}$

Não obstante seja desejável que a prestação de serviços públicos prime pela qualidade e baixo custo, a questão, como coloca, acaba por carecer de pressupostos sólidos que the dêem subsídio. Em outras palavras, toda e qualquer informação pode acabar impregnada de vazio ideológico no momento em que o valor que se pretendia imprimir não venha acompanhado das bases científicas e dos mecanismos lógicos que the dêem fundamento. Embora o documento governamental inegavelmente busque o que poderia ser tido como o ideal no prestação dos serviços públicos, a assertiva parece desvincular-se da realidade à medida que desconsidera a importância da seleção dos meios para a obtenção dos resultados, como se um objetivo fosse algo étereo que se persiga simplesmente com o força do pensamento.

Como procuramos demonstrar no decorrer do texto, a eficiência está necessariamente ligada aos meios, à medida que estes se fazem primordiais para o atingimento dos fins, em sua plenitude. Não poder-se-ia cogitar a busca dos fins pelos fins, descurada de qualquer controle em relação aos meios. A eficiência não sobrevive somente dos resultados, mas também na seleção dos melhores meios para atingi-los em sua plenitude.

E o problema não se circunscreve exclusivamente a essa questão, posto que o fator ético também deve ser considerado. A velha expressão "os fins justificam os meios" não pode mais encontrar guarida em um Estado que se pretenda "Democrático de Direito". Por certo toda e qualquer ação torna-se imoral e mesmo ilícita quando se desapega dos valores fundamentais que norteiam o Estado moderno.

\section{7. - EFICIÊNCIA NA ADMINISTRAÇÃO DA "RES" PÚBLICA - VISÃO} CRÍTICA - A eficiência não é simplesmente um rótulo que sobreviva dos adjetivos

13 Plano Diretor da Reforma do Aparelho do Estado, p. 23.

14 Ibid., passim.

15 Os assim denominados "setores do Estado" e seus respectivos conceitos foram apontados na página 52 e seguintes do Plano Diretor da Reforma do Aparelho do Estado. 
que lhe dêem aqueles que venham a analisar os atos praticados pelo administrador público. Mais que isso, trata-se de poder-dever do administrador público, como já ensinado há tempos por Hely Lopes Meirelles, elevado a princípio constitucional expresso. extensível a todo e qualquer agente público, que no desempenho funcional deverá observar a eficiência como um dos deveres que lhe sejam mais caros.

Não se trata simplesmente de ser um bom agente público, mas do "dever de ser un bom agente público", que agrega em uma de suas facetas o dever de agir :icientemente, da mesma forma como seria a observância de todos os demais princípios da Admiristração Pública (implícitos e expressos), e comandos normativos deles decorrentes.

A partir do momento em que o Estado foi se desvinculando da noção personalista que lhe imprimiam até o fim do Século XIX, com a hegemonia do Estado liberal, passou-se a idealizar concretamente uma feição de Administração Pública que dissesse respeito efetivamente, como o próprio nome sugere, a "administrar o que é público". o que é coletivo, o que pertence a todos a a nenhum ao mesmo tempo.

O novo constitucionalismo e a expansão das suciedades democraticamente organizadas veio a exigir constante e gradual transparência na Administração Públia, em unu processo legiferante e contínuo de aquisição de novos direitos, inclusive metaindividuais, e de solidificação das garantias fundamentais, paralelamente a um movimento crescente na busca de um maior controle pela sociedade das ações do Poder Público, dos gastos públicos e dos serviços prestados à população.

Nesse contexto, a eficiência encontrou ambiente propício à sua inserção no direito administrativo brasileiro, embora pouco tenha sido estudada e muito ainda haja por fazer para o delineamento do instituto. Parte-se, por vezes, do errôneo pressuposto de que as empresas privadas são exemplos de eficiência a ser seguidas, a ponto do Governo Federal recomendar expressamente a adoção de técnicas próprias da iniciativa privada na gestão do patrimônio público, por meio da Administração Pública Gerencial.

Embora o executivo tenha tido o bom senso de não confudi-las, vale ressaltar que a iniciativa privada estará sempre voltada ao lucro, com todas as conseqüências dai advindas.

As empresas privadas estão efetivamente assentadas sobre premissas absolutamente distintas daquelas que devem ser perseguidas pelo Poder Público. Toda a história das relações comerciais e empresariais estão relacionadas indubitavelmente à percepção de numerário e sua aplicação de forma a multiplicá-lo. Já o fim último da Administração Pública é o atingimento do interesse público. Daí os processos, mecanismos de atuação, estrutura dos órgãos e especialmente regime jurídico serem, inexoravelmente, distintos e em alguns pontos inconciliáveis com aqueles perseguidos pela iniciativa privada.

A eficiência, muito mais que um pressuposto da assim denominada administração gerencial, constitui dever, indeclinável e extensível a todo agente público. Cuida-se da busca contínua do aperfeiçoamento no desempenho das funções públicas que lhe sejam conferidas, tendo como "norte" a consciência da extrema importância e relevância de cuidar daquilo que é de todos sem ser de ninguém, do bem, do 
patrimônio, que constitui precisamente a soma dos esforços coletivos que através de gerações vieram a construir um país.

\section{BIBLIOGRAFIA}

BANDEIRA DE MELLO, Celso Antônio. Curso de Direito Administrativo. 12.ed., rev., atual. e ampl. São Paulo: Malheiros, 2000. p. 845.

BRASIL. Presidência da República. Ministério da Administração Federal e Reforma do estado. Câmara da Reforma do Estado. Plano Diretor da Reforma do Aparelho do Estado. Brasília: Presidência da República e Ministério da Administração Federal e Reforma do Estado, 1995. p. 84.

DI PIETRO, Maria Sylvia Zanella. Direito Administrativo. 11.ed. São Paulo: Atlas, 1999. p. 674.

Parcerias na Administração pública: concessão, permissão, franquia, terceirização e outras formas. 3.ed. rev. e ampl. São Paulo: Atlas, 1999. p. 328.

FIGUEIREDO, Lúcia Valle. Curso de Direito Administrativo. 4.ed. rev., ampl. e atual. São Paulo: Malheiros, 2000. p. 622.

LIMA, Ruy Cime. Princípios de Direito Administrativo. 5.ed. São Paulo: Revista dos Tribunais, 1982. p. 219.

MEIRELLES, Hely Lopes. Direito Administrativo Brasileiro. 25.ed. atualizada por Eurico de Andrade Azevedo, Délcio Balestero Aleixo, José Emmanuel Burle Filho. São Paulo: Malheiros, 2000. p. 765.

ROCHA, Carmem Lúcia Antunes. Princípios da Administração Pública. Belo Horizonte: Del Rey, 1996.

SARMENTO, Daniel. Constituição e Globalização: A Crise dos Paradigmas do Direito Constitucional. Revista de Direito Administrativo. Rio de Janeiro: Renovar, no 215: 19-34, Jan./Mar. 1999.

SILVA, José Afonso da. Curso de Direito Constitucional Positivo. 12.ed. rev. e atual. São Paulo: Malheiros, 1996. p. 818.

ZANCANER, Weida. Razoabilidade e Moralidade na Constituição de 1988. Revista Trimestral de Direito Público. 


\section{Curso de Prática Forense Cível e Comercial}

José de Souza Gama

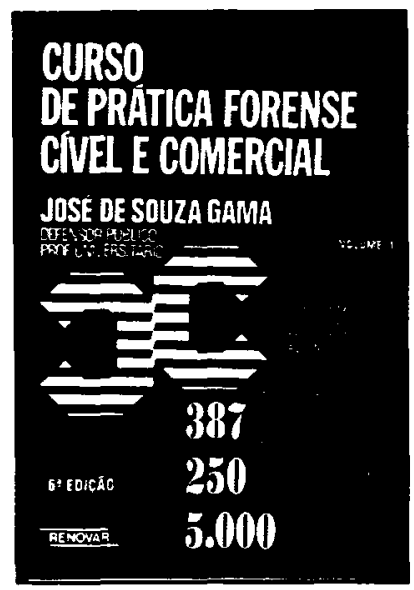

O leitor encontrará nesta obra vinte capítulos didaticamente dispostos, objetivando facilitar o ensino do professor e a aprendizagem do alunado. Cada capítulo é composto basicamente de texto legal, da hipótese (modelo), da jurisprudência e dos exercícios. Seguindo a estrutura do vigente Código de Processo Civil, será encontrada uma série de exercícios que se referem aos casos diários do advogado, e, ao praticá-los, estará aprendendo.

Ref. 0040

1.692 págs.
Cartonado 2 vols.

Form. 16x23 $1996-6^{2}$ ed.

\section{Curso de Prática Forense Penal}

José de Souza Gama

Esta obra tem como objetivos básicos facilitar o ensino. a aprendizagem e prática, usando o método "Aprenda fazendo". Os exercícios são criativos, variados. estimulantes, e a maior parte já foi testada em sala de aula, com excelente resultado. A obra segue rigorosamente a ordem estabelecida no vigente Código de Processo Penal.

Ref. 0026

Form. 16x23
Cartonado 1999
950 págs. $13^{\mathrm{a}}$ ed.

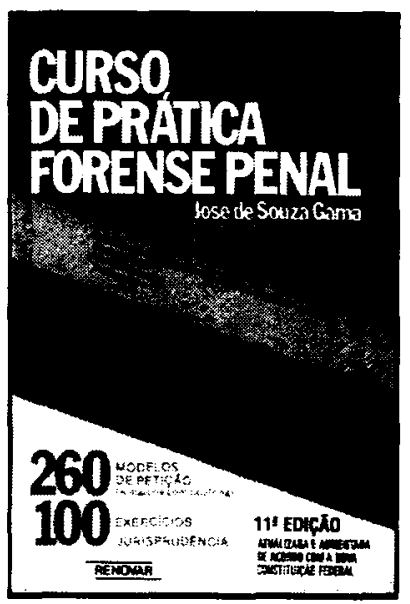

